\title{
Patterns and predictors of treatment initiation and completion in patients with chronic hepatitis $C$ virus infection
}

This article was published in the following Dove Press journal:

Patient Preference and Adherence

3 April 2012

Number of times this article has been viewed

\author{
Brian T Clark ${ }^{1,2}$ \\ Guadalupe Garcia-Tsao ${ }^{1,2}$ \\ Liana Fraenkel ${ }^{1,2}$ \\ 'Veterans Administration, Connecticut \\ Healthcare System, West Haven, \\ ${ }^{2}$ Department of Internal Medicine, \\ Yale University School of Medicine, \\ New Haven, CT, USA
}

Objectives: Guidelines for hepatitis $\mathrm{C}(\mathrm{HCV})$ strongly recommend antiviral treatment for patients with more severe liver disease given their increased risk of developing cirrhosis and other liver-related complications. Despite the proven benefits of therapy, $70 \%-88 \%$ of patients chronically infected with HCV do not undergo treatment. The goal of this paper is to describe patterns of treatment initiation among patients with both mild and severe disease and to assess the factors that are associated with treatment initiation and completion.

Methods: Subjects completed previously validated questionnaires to ascertain sociodemographic characteristics, choice predisposition, and clinical characteristics prior to meeting with the hepatologist to discuss treatment initiation and were followed for 12 months. We examined the association between patient characteristics and treatment patterns controlling for liver disease severity.

Results: Of the 148 eligible subjects entered into our study, 55 (37\%) initiated treatment during the 12-month follow-up period. Of the 86 subjects with severe liver disease, $43(50 \%)$ initiated treatment. Financial barriers and geographic access to care were the most common reasons for treatment deferral. Of the 55 patients initiating treatment, 24 (44\%) discontinued treatment, with intolerance of side effects being the most common reason for discontinuation. After adjusting for liver disease severity, patient choice predisposition (prior to discussion with their provider) was strongly associated with initiation of treatment, while sociodemographic characteristics were not.

Conclusion: Treatment initiation did align with current recommendations (patients with severe disease were more likely to initiate treatment), however, rates of treatment initiation and completion were low. Patient choice predisposition is the strongest predictor of treatment initiation, independent of disease severity. Improving individualized treatment outcomes for patients with chronic HCV requires efforts at identifying patients' choice predisposition, and improving access for those wishing to initiate therapy.

Keywords: barriers, access, preferences, utilization, adverse events

\section{Introduction}

Hepatitis $\mathrm{C}(\mathrm{HCV})$ is a major public health burden with an estimated 180 million people infected worldwide. ${ }^{1}$ Data from the National Health and Nutrition Examination Survey (Centers for Disease Control and Prevention, Atlanta, GA) between 1999 and 2002 estimate a prevalence of HCV infection of $1.6 \%$ in the US population, affecting more than 4 million Americans. ${ }^{2}$ US veterans are disproportionately affected, with a seroprevalence of $5.4 \% .{ }^{3} \mathrm{Up}$ to $22 \%$ of patients with chronic HCV will develop cirrhosis over 20 years. ${ }^{4}$ Patients that develop cirrhosis are at risk for hepatic
Correspondence: Brian T Clark Yale School of Medicine, Department of Internal Medicine, PO Box 208033, New Haven, CT 06520, USA

$\mathrm{Tel}+\mathrm{I} 20393257$ I I ext 5914

$\mathrm{Fax}+\mathrm{I} 2039374392$

Email brian.clark@yale.edu 
decompensation (30\% over 10 years) and development of hepatocellular carcinoma ( $1 \%-3 \%$ per year). ${ }^{5}$ Chronic HCV infection is associated with both increased liver-related and overall mortality. ${ }^{6}$

Sustained virological response (SVR) to treatment decreases progression to cirrhosis and incidence of hepatocellular carcinoma and improves survival. ${ }^{7-9}$ At the time of this study protocol, standard treatment for $\mathrm{HCV}$ consisted of the combination of pegylated interferon and ribavirin, which yields SVR in roughly $50 \%$ of patients. ${ }^{1,10}$ As of October 2011, new guidelines recommend the addition of a protease inhibitor (boceprevir or telaprevir) to previous standard therapy. ${ }^{11}$ Triple therapy regimens such as these yield SVR ranging from $67 \%-76 \%$ in treatment-naïve patients. ${ }^{12-17}$ However, despite the proven benefits of therapy, $70 \%-88 \%$ of patients chronically infected with HCV do not undergo treatment. ${ }^{18-22}$

Consensus panels suggest that patient preferences guide treatment decisions in patients with mild disease. ${ }^{1,23}$ In contrast, guidelines strongly recommend antiviral treatment for patients with more severe disease (portal or bridging fibrosis and moderate inflammation on liver biopsy) given their increased risk of developing cirrhosis and other liver-related complications. ${ }^{1,23}$ Among treatmenteligible patients, the most common reason for not initiating therapy is patient refusal. ${ }^{18-22}$ Treatment efficacy is further limited by intolerance to side effects, with treatment discontinuation rates secondary to adverse events as high as $21 \%{ }^{10,12-17,24,25}$

To the best of our knowledge, no studies have evaluated the barriers and specific patient characteristics that are associated with failure to initiate treatment or discontinuation of treatment in well-informed, motivated, and treatment-eligible patients with chronic HCV. Moreover, previous studies have not distinguished between those with mild and those with more severe liver disease. Understanding the specific factors influencing patients' decisions regarding treatment initiation, deferral, and discontinuation are central to improving the outcomes of this widespread disease.

In this study, we followed treatment-naïve patients who met eligibility criteria and were being offered pegylated interferon and ribavirin for chronic HCV over the course of 12 months. The goal of this paper is to describe patterns of treatment initiation among patients with both mild and severe disease and to assess the factors that correlate with treatment initiation and completion, particularly among patients with severe disease for whom treatment is strongly recommended.

\section{Subjects and methods Subjects}

The study was conducted at two sites: the Yale University School of Medicine Liver Clinic (New Haven, CT), and the Veterans Administration (VA) Connecticut Healthcare System Liver Clinic (West Haven, CT). The same hepatologists attend both clinics. Consecutive patients eligible for treatment of $\mathrm{HCV}$ were recruited. Eligibility criteria included treatmentnaïve patients with chronic HCV of a known genotype, and either clinical evidence of cirrhosis or a liver biopsy within the preceding 2 years. Inclusion criteria were based on recommendations from the National Institutes of Health (NIH), American Association for the Study of Liver Diseases (AASLD), and the VA at the time of the study which stated that patients with chronic HCV and evidence of chronic hepatitis on liver biopsy should be offered therapy with the combination of pegylated interferon and ribavirin regardless of genotype or the presence of symptoms. ${ }^{1,23,26}$ Exclusion criteria were conditions that are considered contraindications to therapy, specifically: major uncontrolled depression, solid organ transplant, an autoimmune disorder that could be exacerbated by interferon, untreated thyroid disease, pregnancy or unwillingness to comply with contraception, and marked anemia or known hypersensitivity to pegylated interferon or ribavirin. ${ }^{1,23,26}$ Subjects were recruited by the treating physician, advanced practice registered nurse, or the research nurse at the time of liver biopsy appointment. Subjects who did not have a scheduled liver biopsy were invited to participate by clinic staff and consented by the research nurse on the day of their study visit. ${ }^{27}$ Liver fibrosis was staged according to the Batts and Ludwig classification ${ }^{28}$ (a modification of the Scheuer classification) in which Stage 0 corresponds to no fibrosis, Stage 1 is portal fibrosis, Stage 2 is periportal fibrosis, Stage 3 is bridging fibrosis, and Stage 4 is cirrhosis. Prior to ascertaining baseline data, all subjects participating in this study underwent a formalized education class regarding the disease, its natural history, course and treatment options, and their side effects. They were also informed of the stage of their disease. Subsequently, baseline data were collected, followed directly by the initial visit with their hepatologist to discuss treatment initiation.

All participants completed written informed consent. The protocol was approved by the Human Subjects Subcommittee of the VA Connecticut Healthcare System and by the Yale School of Medicine.

\section{Data collection}

All data were collected in a private room with the help of a research nurse. All subjects completed previously validated 
questionnaires to ascertain sociodemographic characteristics, alcohol and drug use, ${ }^{29-31}$ social support, ${ }^{32}$ overall health status, ${ }^{33}$ trust in physician, ${ }^{34}$ and physical, social, and emotional impact of HCV (quality of life scale). ${ }^{35}$ Medical comorbidities were defined based on patients' responses to a predefined list of six conditions: hypertension, diabetes, lung disease, kidney disease, peptic ulcer disease, or mental illness. ${ }^{36}$ Depression was measured using a two question instrument that evaluates depressed mood and anhedonia. This instrument has been validated in a VA setting against six other instruments. ${ }^{37}$ Baseline choice predisposition was ascertained based on a previously validated scale ranging from zero (I am certain that I do not want to be treated) to ten (I am certain that I do want to be treated). ${ }^{38}$ In this study, choice predisposition reflects patient preference for treatment measured prior to completing a decision support tool and prior to meeting with their hepatologist to discuss initiation of treatment.

Baseline data were collected in a face-to-face interview prior to the patient-physician visit during which treatment initiation was discussed. Follow-up data was collected in telephone interviews conducted 1, 3, 6, and 12 months later. Up to three attempts were made to contact each subject at each time point. During follow-up interviews the research assistant elicited patients' initial treatment decision, their treatment decision at the time of the interview, and whether they had initiated treatment. Reasons for not having initiated treatment and whether treatment was continuing, completed, or discontinued were also documented.

\section{Statistical analysis}

Subject characteristics and survey data were entered into SAS computer files (SAS software, v 9.2; SAS Institute Inc, Cary, NC). Age, social support, HCV-related quality of life, trust in physician, and choice predisposition were treated as continuous variables. The remaining characteristics were treated as categorical variables. Health status was categorized as excellent or very good versus good, fair or poor. Severity of liver disease was categorized as mild (fibrosis Stages 0-2) or severe (fibrosis Stages 3-4 and/or clinical cirrhosis). Alcohol and drug use were classified as ever versus never use.

Using descriptive statistics we reported subjects' choice predisposition (treatment preference prior to discussing treatment initiation with their hepatologist), intent to initiate treatment after discussion with their hepatologist, the number of subjects that actually initiated treatment, and of those that initiated treatment, the number that discontinued treatment.
We then examined the association between patient characteristics and treatment patterns using the Mann-Whitney U-test and the $\chi^{2}$ statistic for continuous and categorical variables, respectively. We compared sociodemographic and clinical characteristics among: (1) patients that initiated treatment versus those that did not initiate treatment; (2) patients with severe disease that initiated treatment versus did not initiate treatment; and (3) patients that completed treatment versus those that did not complete treatment.

\section{Results \\ Subject characteristics}

Of 212 eligible subjects, 178 agreed to participate in the study, and 148 completed the baseline and subsequent follow-up surveys. Thirty subjects did not complete baseline surveys for logistical reasons as previously described. ${ }^{27}$ Ninety-three percent of subjects completed two or more follow-up interviews over the 12-month period, and 93\% completed interviews at least 3 months from the baseline interview.

Characteristics for subjects grouped by underlying liver disease severity are described in Table 1 . The mean $( \pm \mathrm{SD})$ age of the sample was $51 \pm 8$ years, $87 \%$ were male, $45 \%$ were non-Hispanic white, and $34 \%$ were black. The median HCV-related quality of life score was 19 with range of $0-89$ (possible range $0-100$ with higher scores indicating poorer quality of life). Twenty percent reported excellent or very good health status. Sixty-two (42\%) had mild liver disease (fibrosis Stages 0-2) and 86 (58\%) had severe disease (fibrosis Stages 3-4, and/or clinical cirrhosis).

\section{Choice predisposition}

Prior to meeting with their hepatologist, subjects' median choice predisposition score was seven with a range of $0-10$. Higher scores represent greater preference towards undergoing treatment. Subjects with mild versus severe disease had median choice predisposition scores of five and eight, respectively $(P=0.007)$.

\section{Treatment initiation}

After completing a decision support tool and meeting with their hepatologist, 83 subjects (56\%) reported that they intended to initiate treatment, $48(32 \%)$ reported that they declined treatment, and $17(12 \%)$ were undecided. Of the 83 subjects intending to undergo treatment, 33 (40\%) had not initiated treatment by month 12 . Twenty-four of these subjects (73\%) had severe disease. Among the 48 subjects that reported declining treatment, none had initiated treatment by month 12 . 
Table I Subjects' characteristics by disease severity $(\mathrm{N}=148)$

\begin{tabular}{|c|c|c|c|}
\hline Characteristic & $\begin{array}{l}\text { Mild disease } \\
\text { Number (\%) }\end{array}$ & $\begin{array}{l}\text { Severe disease } \\
\text { Number (\%) }\end{array}$ & $\begin{array}{l}\text { All patients } \\
\text { Number (\%) }\end{array}$ \\
\hline Total number (\%) & $62(42)$ & $86(58)$ & $148(100)$ \\
\hline Age (mean, SD) & $51 \pm 8$ & $52 \pm 8$ & $51 \pm 8$ \\
\hline Male & $54(87)$ & $74(86)$ & $128(87)$ \\
\hline Hispanic & $8(13)$ & $12(14)$ & $20(14)$ \\
\hline \multicolumn{4}{|l|}{ Race } \\
\hline White (non-Hispanic) & $32(52)$ & $35(4 I)$ & $67(45)$ \\
\hline Black & $16(26)$ & $34(40)$ & $50(34)$ \\
\hline Married & $16(26)$ & $20(23)$ & $36(24)$ \\
\hline At least some college education & $34(55)$ & $33(38)$ & $67(45)$ \\
\hline Income $>\$ 60,000$ & $5(8)$ & $3(4)$ & $8(5)$ \\
\hline Employed & $26(42)$ & $31(36)$ & $57(39)$ \\
\hline Veteran clinic & $49(79)$ & $49(57)$ & $98(66)$ \\
\hline \multicolumn{4}{|l|}{ Number of medical comorbidities ${ }^{\mathrm{a}}$} \\
\hline Zero & $18(29)$ & $23(27)$ & $4 \mid(28)$ \\
\hline One & $26(42)$ & $33(38)$ & $59(40)$ \\
\hline Two or more & $18(29)$ & $30(35)$ & $48(32)$ \\
\hline Excellent or very good overall health status ${ }^{\mathrm{b}}$ & $16(26)$ & $13(15)$ & $29(20)$ \\
\hline HCV-related quality of life ${ }^{c}$ (median, range) & $17(0-89)$ & $21(0-89)$ & $19(0-89)$ \\
\hline Trust in physician ${ }^{\mathrm{d}}$ (median, range) & $73(45-100)$ & $70(45-100)$ & $70(45-100)$ \\
\hline Patient choice predisposition ${ }^{\mathrm{e}}$ (median, range) & $5(0-10)$ & $8(0-10)$ & $7(0-10)$ \\
\hline HCV genotype I & $52(84)$ & $73(85)$ & $125(85)$ \\
\hline HCV genotype 2 & $10(16)$ & $13(15)$ & $25(16)$ \\
\hline \multicolumn{4}{|l|}{ Alcohol abuse } \\
\hline Never & $18(29)$ & $34(40)$ & $52(35)$ \\
\hline Ever & $44(7 I)$ & $52(61)$ & $96(65)$ \\
\hline Current & $2(3)$ & $5(6)$ & $7(5)$ \\
\hline \multicolumn{4}{|l|}{ Substance abuse } \\
\hline Never & $6(10)$ & $14(16)$ & $20(14)$ \\
\hline Ever & $56(90)$ & $72(84)$ & $128(87)$ \\
\hline Current & $6(10)$ & $5(6)$ & II (7) \\
\hline History of depression ${ }^{f}$ & $31(50)$ & $53(62)$ & $84(57)$ \\
\hline
\end{tabular}

Notes: 'Based on subjects' response to a predefined list of six comorbidities: hypertension, diabetes, lung disease, kidney disease, peptic ulcer disease, and mental illness; 'based on subjects' response to a validated questionnaire: (In general, I would say that my health is ... poor, fair, good, very good or excellent); 'based on a previously validated hepatitis $\mathrm{C}(\mathrm{HCV})$ quality of life scale encompassing eleven questions. Range of total score is 0 - 100 with higher scores representing worse quality of life; 'based on a previously validated trust in physician scale. Range of total score is $0-100$ with higher scores representing greater trust in physician; ${ }^{\mathrm{e}} \mathrm{choice}$ predisposition was ascertained based on a previously validated scale ranging from zero ( $\mathrm{am}$ certain that I do not want to be treated) to ten (I am certain that I do want to be treated). Higher scores reflect greater preference towards undergoing treatment; 'depression was measured using a previously validated two-question instrument that evaluates depressed mood and anhedonia.

Of these, $31 \%$ had severe disease. Treatment initiation patterns by disease severity are further detailed in Figure 1.

Reasons for not initiating treatment among subjects who had initially intended to undergo treatment are listed in Table 2. Financial barriers and geographic access to care were the most common reasons for treatment deferral. Some subjects changed their mind regarding their desire for treatment and others remained undecided during the follow-up period. Some reported that their work or school responsibilities made it difficult to find the right time to initiate treatment. Three subjects reported that they had failed to follow-up with the clinic in order to initiate treatment. Seven subjects did not specify a reason for treatment deferral.

\section{Course among subjects initiating treatment}

Details of treatment course by disease severity are described in Figure 2. Fifty-five of 148 eligible subjects (37\%) initiated treatment for $\mathrm{HCV}$ during the 12-month follow-up period. Forty-three $(78 \%)$ of these subjects had severe disease. Of the 55 subjects who started treatment, 24 (44\%) discontinued therapy during the follow-up period, of whom $18(75 \%)$ reported that treatment was discontinued by their physician while the remaining six subjects $(25 \%)$ elected to discontinue treatment, most commonly because of persistent side effects. None of these subjects reinitiated treatment after discontinuation. Toxicity was the most common reason for discontinuing treatment overall, whereas a lack 


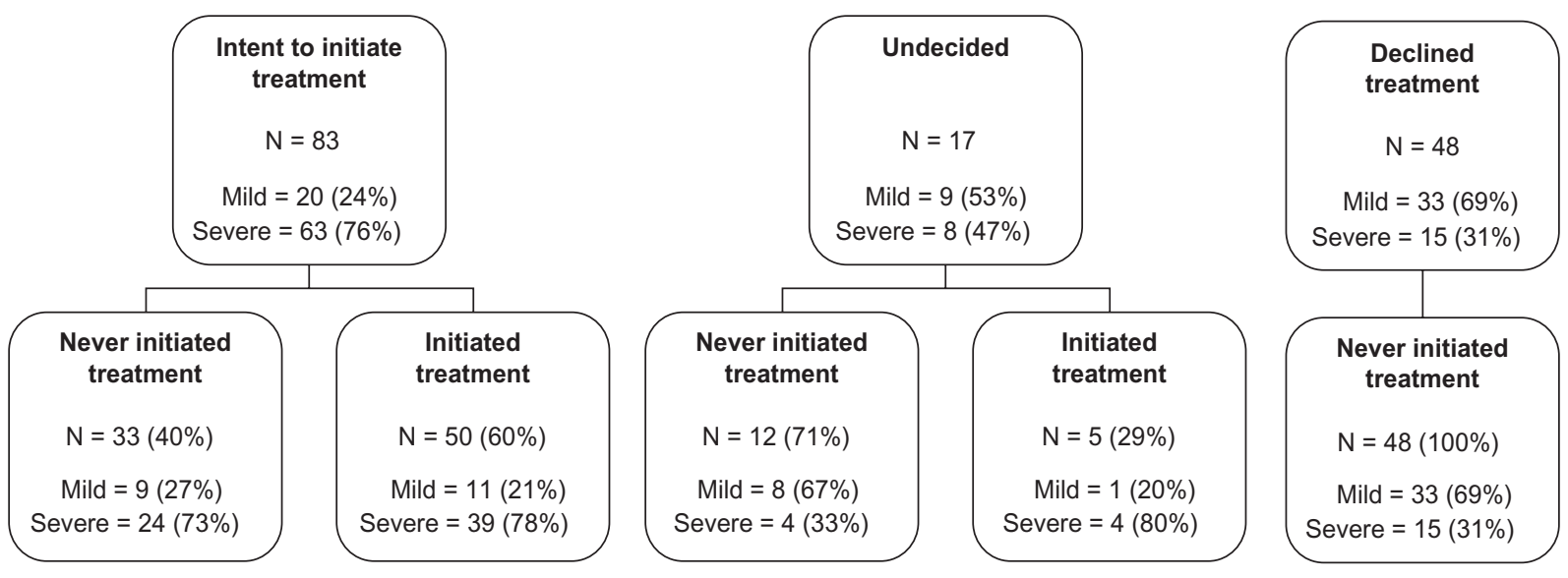

Figure I Treatment initiation patterns in 148 patients with chronic hepatitis C by disease severity from initial survey (after discussion with hepatologist) to follow-up after 12 months.

Notes: Mild liver disease defined by fibrosis Stages 0-2. Severe liver disease defined by fibrosis Stages 3-4 and/or clinical cirrhosis.

of viral response was the most common reason physicians discontinued treatment (Table 3).

\section{Patterns based on liver disease severity}

Among the 62 subjects with mild disease, 20 (32\%) reported that they intended to initiate treatment and $12(19 \%)$ actually initiated treatment within 12 months of follow-up. Of these, five (42\%) discontinued treatment. Among the 86 subjects with severe disease, 63 (73\%) reported that they intended to initiate treatment and $43(50 \%)$ actually initiated treatment. Of these, 19 (44\%) discontinued treatment.

\section{Relationship of subject characteristics and treatment patterns}

The association between subject characteristics and initiation of treatment is described in Table 4A (categorical

Table 2 Patient-reported reasons for not initiating treatment in patients that initially expressed intent to undergo treatment

\begin{tabular}{lll}
\hline & $\begin{array}{l}\text { All patients } \\
(\mathbf{n}=\mathbf{3 3})\end{array}$ & $\begin{array}{l}\text { Severe disease } \\
(\mathbf{n}=\mathbf{2 4})\end{array}$ \\
\hline Financial/insurance & 7 & 5 \\
Transportation/geographic access & 7 & 5 \\
Decided against treatment & 5 & 2 \\
Timing & 5 & 4 \\
Missed appointments/no follow-up & 3 & 2 \\
Medical comorbidities & 3 & $\mathrm{I}$ \\
$\begin{array}{l}\text { Indecision with regard to } \\
\text { treatment preference }\end{array}$ & 2 & 0 \\
Unstable living situation or & $\mathrm{I}$ & $\mathrm{I}$ \\
inadequate support & & $\mathrm{I}$ \\
$\begin{array}{l}\text { Transplant-listed } \\
\text { (ineligible for treatment) }\end{array}$ & $\mathrm{I}$ & \\
\hline Notes:Posponit & &
\end{tabular}

Notes: aPostponing treatment until able to optimize timing in regards to school, work or other issues; bthis subject developed decompensation and became transplantlisted after enrollment. Some subjects provided more than one response. variables) and Table 4B (continuous variables). In bivariate analysis, we found that liver disease severity and choice predisposition were associated with initiation of treatment among all patients. HCV-related quality of life and age were borderline associated with initiation of treatment among all patients. In subjects with severe liver disease, only choice predisposition remained associated with initiation of treatment (Table 4A and B). We found no association between treatment initiation and age, genotype, gender, race, employment or marital status, education, history of depression, substance abuse, site of care, health status, trust in physician, HCV-related quality of life or social support score.

Associations between subject characteristics and completion of treatment are described in Table 5A (categorical variables) and Table 5B (continuous variables). Being married was the only factor associated with treatment completion. No other factors were associated with treatment completion, including genotype, disease severity, choice predisposition, HCV-related quality of life, trust in physician, history of depression or substance abuse, and sociodemographic characteristics.

\section{Discussion}

We found that in a population of treatment-eligible patients with chronic $\mathrm{HCV}$, a relatively small proportion initiated treatment with pegylated interferon and ribavirin, and far fewer completed the course of therapy, within 12 months of follow-up. Of significant concern was that a substantial proportion of patients with severe liver disease (fibrosis Stages 3 or 4 or clinical cirrhosis) refused therapy or failed to initiate treatment. Of those with severe disease, only $28 \%$ 


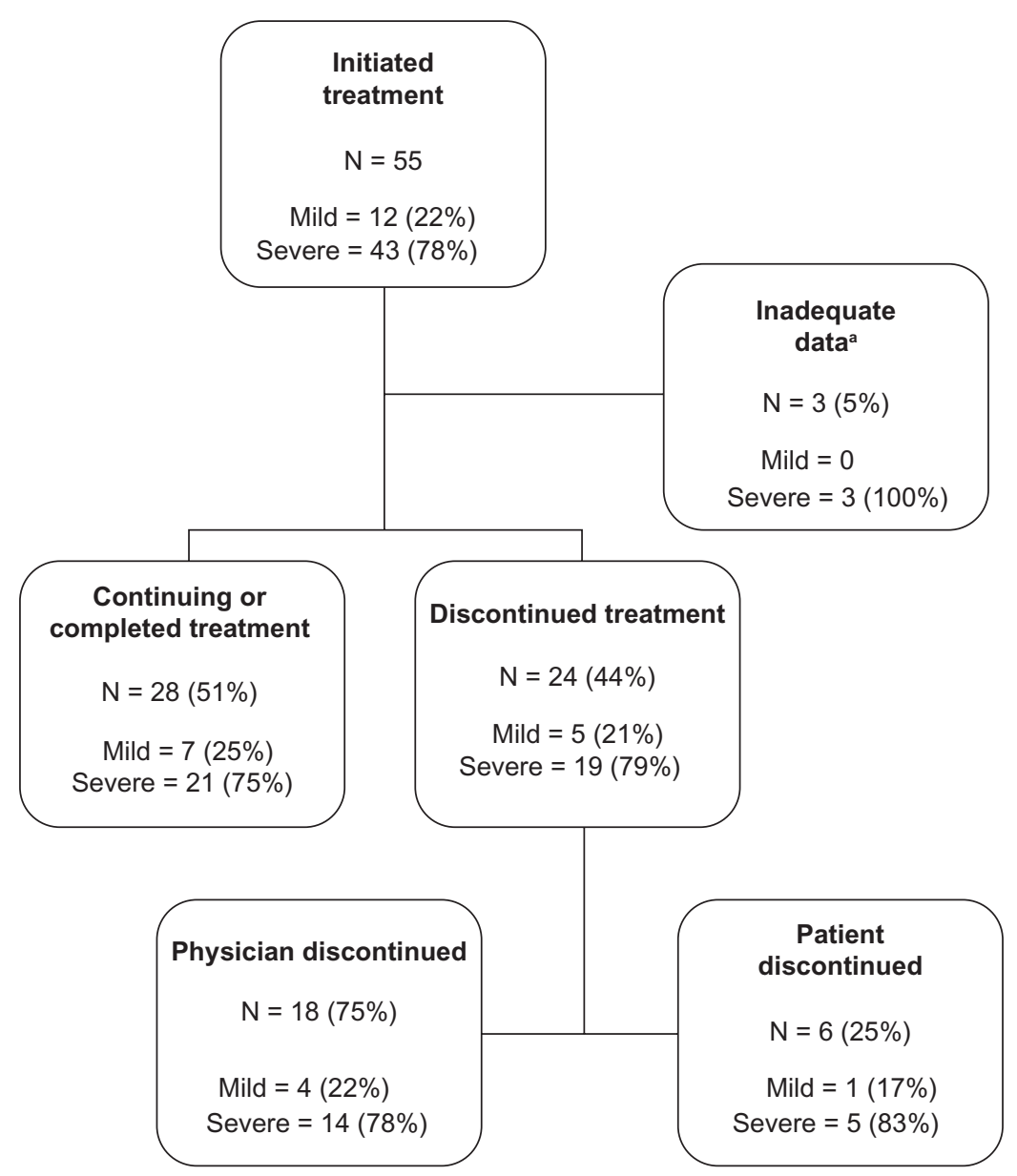

Figure 2 Treatment completion patterns in 55 patients who initiated treatment by disease severity over the course of 12 months.

Notes: ${ }^{a}$ Subjects gave no reason for not initiating treatment and completed two or fewer follow-up surveys, including no follow-up at 6 month or 12 month surveys. Mild liver disease defined by fibrosis Stage $0-2$. Severe liver disease defined by fibrosis Stages 3-4 and/or clinical cirrhosis.

completed a course of therapy. Treatment patterns did align with current treatment recommendations (disease severity was positively associated with initiation of treatment). However, this study highlights the persistence of suboptimal treatment initiation and completion patterns particularly in patients with advanced disease. This is also the first study documenting that patient choice predisposition is a strong predictor of treatment initiation, independent of disease severity. We would argue that with currently available therapies, optimization of treatment for hepatitis $\mathrm{C}$ requires attention to both the evaluation of patients' choice predisposition, and the reduction of barriers to treatment initiation.

While there is generally low uptake and completion of therapy in $\mathrm{HCV}$, it is most important to be able to identify patients with severe disease who are at higher risk for failing to initiate treatment. In this study, we found a strong association between patient choice predisposition and initiation of treatment, independent of underlying liver disease severity. This finding may support the practice of measuring choice predisposition (using a previously validated eleven-point

Table 3 Patient-reported reasons for discontinuing treatment

\begin{tabular}{lll}
\hline Physician discontinued & $(\mathbf{n}=\mathbf{~ I 8 )}$ & Patient discontinued \\
\hline Lack of viral response & 5 & Side effects/Intolerance \\
Severe side effects & 4 & Insurance \\
Social factors & 2 & Social factors \\
Medical comorbidities & $\mathrm{I}$ & No specific reason given \\
Non-compliance & $\mathrm{I}$ & $\mathrm{I}$ \\
No specific reason given to patient & 7 & I \\
\hline
\end{tabular}

Note: Some subjects provided more than one response. 
Table 4A Associations between subject characteristics (categorical) and initiation of treatment

\begin{tabular}{|c|c|c|c|c|}
\hline \multirow[t]{2}{*}{ Characteristic } & \multicolumn{2}{|l|}{$\begin{array}{l}\text { All patients } \\
(N=148)\end{array}$} & \multicolumn{2}{|c|}{$\begin{array}{l}\text { Patients with severe disease } \\
(N=86)\end{array}$} \\
\hline & $\begin{array}{l}\text { Percentage initiating } \\
\text { treatment }(\mathrm{N})\end{array}$ & $P$ value & $\begin{array}{l}\text { Percentage initiating } \\
\text { treatment }(\mathrm{N})\end{array}$ & $P$ value \\
\hline \multicolumn{5}{|l|}{ Race } \\
\hline Non-Hispanic white & $3 I(2 I)$ & 0.18 & $43(15)$ & 0.27 \\
\hline Other & $42(34)$ & & $55(28)$ & \\
\hline \multicolumn{5}{|l|}{ Gender } \\
\hline Male & $36(46)$ & 0.44 & $49(36)$ & 0.53 \\
\hline Female & 45 (9) & & $58(7)$ & \\
\hline \multicolumn{5}{|l|}{ Education } \\
\hline Some college & $34(23)$ & 0.52 & $48(16)$ & 0.83 \\
\hline No college & $40(32)$ & & $51(27)$ & \\
\hline \multicolumn{5}{|l|}{ Marital status } \\
\hline Married & $36(13)$ & 0.88 & $45(9)$ & 0.61 \\
\hline Unmarried & $38(42)$ & & $52(34)$ & \\
\hline \multicolumn{5}{|l|}{ Employment status } \\
\hline Employed & $35(20)$ & 0.68 & $48(15)$ & 0.82 \\
\hline Unemployed & $38(35)$ & & $5 I(28)$ & \\
\hline \multicolumn{5}{|l|}{ History of depression ${ }^{a}$} \\
\hline Yes & $38(26)$ & 0.80 & $44(19)$ & 0.28 \\
\hline No & $36(29)$ & & $56(24)$ & \\
\hline \multicolumn{5}{|l|}{ Alcohol abuse } \\
\hline Ever & $36(35)$ & 0.81 & $52(27)$ & 0.66 \\
\hline Never & $38(20)$ & & $47(16)$ & \\
\hline \multicolumn{5}{|l|}{ Substance abuse } \\
\hline Ever & $38(48)$ & 0.83 & $54(39)$ & 0.08 \\
\hline Never & $35(7)$ & & $29(4)$ & \\
\hline \multicolumn{5}{|l|}{ Site of care } \\
\hline Veteran & $36(35)$ & 0.61 & $53(26)$ & 0.51 \\
\hline Nonveteran & $40(20)$ & & $46(17)$ & \\
\hline \multicolumn{5}{|l|}{ Health status ${ }^{\mathrm{b}}$} \\
\hline Excellent/very good & $34(10)$ & 0.74 & $38(5)$ & 0.37 \\
\hline Good/fair/poor & $38(45)$ & & $52(38)$ & \\
\hline \multicolumn{5}{|c|}{ Number of comorbidities ${ }^{c}$} \\
\hline Two or more & $40(19)$ & 0.67 & $57(17)$ & 0.37 \\
\hline Less than two & $36(36)$ & & $46(26)$ & \\
\hline \multicolumn{5}{|l|}{ Genotype } \\
\hline One & $37(44)$ & 0.34 & $48(35)$ & 0.37 \\
\hline Two & $48(\mathrm{II})$ & & $62(8)$ & \\
\hline \multicolumn{5}{|c|}{ Liver disease severity ${ }^{\mathrm{d}}$ (fibrosis stage) } \\
\hline Severe & $50(43)$ & $<0.01$ & $N / A$ & - \\
\hline Mild & $19(12)$ & & N/A & \\
\hline
\end{tabular}

numeric rating scale $)^{38}$ in clinical practice. This simple screening tool could be used to identify patients with severe disease who are at higher risk of not initiating treatment and may benefit from more targeted education strategies or support. We found no significant association between treatment initiation and sociodemographic characteristics including $\mathrm{HCV}$-related quality of life, when controlling for liver disease severity. Ultimately, identifying the specific factors that drive patient preference or choice predisposition may allow for the development of more targeted interventions to increase the number of eligible patients initiating therapy.

Despite the extensive education provided at both sites, one-quarter of patients with severe disease declined treatment even after discussion with their hepatologist. This suggests 
Table 4B Associations between subject characteristics (continuous) and initiation of treatment

\begin{tabular}{|c|c|c|c|c|c|c|}
\hline \multirow[t]{2}{*}{ Characteristic } & \multicolumn{3}{|c|}{ All patients median (range) } & \multicolumn{3}{|c|}{ Patients with severe disease median (range) } \\
\hline & $\begin{array}{l}\text { Subjects initiating } \\
\text { treatment }(N=55)\end{array}$ & $\begin{array}{l}\text { Subjects not initiating } \\
\text { treatment }(N=93)\end{array}$ & $P$ value & $\begin{array}{l}\text { Subjects initiating } \\
\text { treatment }(N=43)\end{array}$ & $\begin{array}{l}\text { Subjects not initiating } \\
\text { treatment }(N=43)\end{array}$ & $P$ value \\
\hline Age (years) & $5 I(26-64)$ & $53(23-70)$ & 0.05 & $5 I(26-64)$ & $53(36-70)$ & 0.11 \\
\hline Social support score ${ }^{a}$ & $67(18-100)$ & $64(5-100)$ & 0.56 & $64(18-100)$ & $68(5-100)$ & 0.95 \\
\hline HCV-related quality of life $e^{b}$ & $30(0-77)$ & $14(0-89)$ & 0.05 & $25(0-77)$ & $18(0-89)$ & 0.61 \\
\hline Trust in physician ${ }^{c}$ & $73(45-100)$ & $70(45-100)$ & 0.41 & $73(45-100)$ & $66(45-100)$ & 0.18 \\
\hline Choice predisposition $^{d}$ & $10(3-10)$ & $5(0-10)$ & $<0.01$ & $10(3-10)$ & $5(0-10)$ & $<0.01$ \\
\hline
\end{tabular}

Notes: ${ }^{B}$ Based on a previously validated social support scale consisting of 18 questions. Range of total score is $0-100$ with higher scores representing greater social support; bbased on a previously validated hepatitis $\mathrm{C}(\mathrm{HCV})$ quality of life scale encompassing eleven questions. Range of total score is $0-100$ with higher scores representing worse quality of life; 'based on a previously validated trust in physician scale. Range of total score is 0-100 with higher scores representing greater trust in physician; ${ }^{\mathrm{d}}$ choice predisposition was ascertained based on a previously validated scale ranging from zero ( $\mathrm{am}$ certain that I do not want to be treated) to ten ( $\mathrm{am}$ certain that I do want to be treated). Higher scores reflect greater preference towards undergoing treatment.

that patient education alone is insufficient to motivate a significant number of patients with severe disease to accept pegylated interferon and ribavirin for chronic HCV. Further studies will determine whether uptake is higher with triple therapy. Although most of the participants (56\%) reported their intent to initiate treatment after seeing their hepatologists, only 55 of 148 (37\%) actually initiated treatment within the 12 months. Current guidelines from the NIH, AASLD, and VA recommend treatment for all eligible patients with moderate or severe disease, while individualizing treatment plans for patients with mild disease. ${ }^{1,23,26}$ In our study, only $50 \%$ of patients with severe disease initiated treatment, indicating suboptimal treatment initiation rates among patients most in need of treatment.

Our results are consistent with previous studies citing low treatment rates, with only $11.8 \%-30 \%$ of patients chronically infected with $\mathrm{HCV}$ undergoing treatment. ${ }^{18-22,39}$ However, in contrast to our approach, these studies included patients that they considered ineligible for treatment such as patients with active substance abuse, psychiatric comorbidities, advanced cirrhosis, normal liver function tests, or an undetectable viral load. These studies also did not stratify by disease severity. In our study we included only patients that we considered eligible for treatment, who underwent intensive education about chronic $\mathrm{HCV}$, its complications and treatment, and had already followed up with a liver specialty clinic. Moreover, many of our study patients had access to the Hepatitis C Resource Center at the VA Connecticut Health System, which is a multidisciplinary team dedicated to treating patients with active psychiatric and substance abuse comorbidities. This method of individualizing care for these patients with relative, not absolute, contraindications to treatment would be expected to improve the ability to capture more individuals as "suitable" candidates for treatment. Despite the abundance of patient support and education, and the exclusion of treatment-ineligible patients from our study, we found that only a minority of patients initiated treatment. These results indicate that there are significant barriers to initiating treatment beyond screening and education.

Reasons for not initiating treatment in our subjects fell into two major categories, system factors and patient-driven factors. System factors included geographic barriers (inability to arrange transportation to appointments or to find a provider within a reasonable distance), financial limitations, and inadequate insurance coverage. Financial concerns were a significant barrier even in the veteran population, where non-service connected veterans have to pay $\$ 9$ for each prescription and $\$ 50$ copayment for each specialty clinic visit. The most common patient factors reported by the subjects in this study included that they had missed their appointments, had difficulty arranging sufficient time away from their responsibilities (eg, family, school, work) to commit to treatment, and had continued uncertainty regarding the risk-benefit tradeoffs of currently available therapies. System factors predominated for subjects with severe disease. These results suggest that interventions aimed at reducing geographic and financial barriers may increase the number of patients with severe disease willing to initiate therapy.

In addition to suboptimal treatment initiation rates, treatment completion rates were also low (19\% overall at 12 months) among our population within the 12 months of our study. Half of the patients that initiated treatment either discontinued treatment or were lost to follow-up. These discontinuation rates are similar to other cited studies of non-clinical trial patients. ${ }^{20,39,40}$ Our results are also consistent with studies showing poorer treatment response rates in patients with genotype 1 , severe liver disease, and age greater than 40 years; characteristics that predominated among subjects in this study who initiated treatment. ${ }^{10,41,42}$ 
Table 5A Associations between subject characteristics (categorical) and completion of treatment

\begin{tabular}{|c|c|c|}
\hline Characteristic & $\begin{array}{l}\text { Percentage } \\
\text { completing } \\
\text { treatment }(\mathbf{N})\end{array}$ & $P$ value \\
\hline \multicolumn{3}{|l|}{ Race } \\
\hline Non-Hispanic white & $45(9)$ & 0.31 \\
\hline Other & $59(19)$ & \\
\hline \multicolumn{3}{|l|}{ Gender } \\
\hline Male & $57(25)$ & 0.31 \\
\hline Female & $38(3)$ & \\
\hline \multicolumn{3}{|l|}{ Education } \\
\hline Some college & $59(13)$ & 0.52 \\
\hline No college & $50(15)$ & \\
\hline \multicolumn{3}{|l|}{ Marital status } \\
\hline Married & $83(10)$ & 0.02 \\
\hline Unmarried & $45(18)$ & \\
\hline \multicolumn{3}{|l|}{ Employment status } \\
\hline Employed & $42(8)$ & 0.20 \\
\hline Unemployed & $61(20)$ & \\
\hline \multicolumn{3}{|l|}{ History of depression ${ }^{\mathrm{a}}$} \\
\hline Yes & $58(14)$ & 0.55 \\
\hline No & $50(14)$ & \\
\hline \multicolumn{3}{|l|}{ Alcohol abuse } \\
\hline Ever & $56(18)$ & 0.66 \\
\hline Never & $50(10)$ & \\
\hline \multicolumn{3}{|l|}{ Substance abuse } \\
\hline Ever & $53(24)$ & 0.85 \\
\hline Never & $57(4)$ & \\
\hline \multicolumn{3}{|l|}{ Site of care } \\
\hline Veteran & $52(17)$ & 0.66 \\
\hline Nonveteran & $58(I I)$ & \\
\hline \multicolumn{3}{|l|}{ Health status ${ }^{b}$} \\
\hline Excellent/very good & $50(5)$ & 0.79 \\
\hline Good/fair/poor & $55(23)$ & \\
\hline \multicolumn{3}{|c|}{ Number of comorbidities ${ }^{c}$} \\
\hline Two or more & $47(9)$ & 0.48 \\
\hline Less than two & $58(19)$ & \\
\hline \multicolumn{3}{|l|}{ Genotype } \\
\hline One & $59(24)$ & 0.19 \\
\hline Two & $36(4)$ & \\
\hline \multicolumn{3}{|c|}{ Liver disease severity (fibrosis stage) } \\
\hline Severe & $53(21)$ & 0.72 \\
\hline Mild & $58(7)$ & \\
\hline
\end{tabular}

Notes: ${ }^{a}$ Depression was measured using a previously validated two-question instrument that evaluates depressed mood and anhedonia; 'based on subjects' response to a previously validated questionnaire: (In general, I would say that my health is ... poor, fair, good, very good or excellent); 'based on subjects' response to a predefined list of six comorbidities: hypertension, diabetes, lung disease, kidney disease, peptic ulcer disease, and mental illness; ${ }^{d}$ staged according to the Batts and Ludwig classification. ${ }^{29}$ Mild disease defined as fibrosis Stages $0-2$. Severe disease defined as fibrosis Stages 3-4 and/or clinical cirrhosis.

Most of our patients had treatment discontinued by their hepatologist because of drug-related toxicity or lack of viral response. Only six patients self-discontinued treatment, mainly due to inability to tolerate side effects. Factors that were associated with initiation of treatment (namely disease severity and choice predisposition) appeared to have no association with completion of treatment. Similarly, the sole factor correlating with treatment completion (marital status) had no association with treatment initiation. While not examined directly in our study, previous studies have shown the addition of telaprevir or boceprevir to pegylated interferon and ribavirin to be associated with similar or increased rates of adverse events, with discontinuation rates of $7 \%-21 \%$ for triple-therapy regimens. ${ }^{12-17,25}$ These results suggest that success rates with currently available drugs will continue to be limited despite efforts to improve screening for HCV and uptake of therapy. Improving the efficacy and tolerability of medication classes will be most crucial to optimize treatment completion rates.

To the best of our knowledge, this is the first study of its kind evaluating both patient preferences immediately prior to discussion about treatment initiation with the patients' treating hepatologist, and patient treatment patterns over time. Other strengths include the exclusion of patients that were not eligible for $\mathrm{HCV}$ treatment and the stratification of patients based on liver disease severity. There are also important limitations to note. Although we recruited patients from both university and VA-based clinics, the majority were from the VA clinics. Thus, our study participants may not be fully representative of other samples that are community-based. Because our study examined pegylated interferon- and ribavirin-based regimens, generalizability to newer triple therapy regimens may be limited. However, the barriers to treatment initiation elucidated in this paper remain independent of the addition of these new medications. Additionally, triple therapy regimens as they currently stand continue to include both pegylated interferon and ribavirin. Finally, given our sample size, the associations found should be replicated in larger study populations.

Although physician-based guidelines for initiating antiviral treatment for eligible patients with chronic HCV are based strongly on disease severity, individual patient preferences are diverse and varied. Our study highlights the association of both disease severity and patient choice predisposition with initiation of antiviral treatment. Elucidating the specific modifiable patient characteristics that determine choice predisposition at the time of discussion of antiviral treatment will be pivotal to optimizing treatment initiation rates in all patients. This is particularly important in patients with more severe disease who are most likely to benefit from treatment. Our study also highlights the importance of addressing systemic barriers to treatment. This is true even for systems that prioritize access, such as the VA. However, despite efforts to increase initiation rates, the high discontinuation rate in 
Table 5B Associations between subject characteristics (continuous) and completion of treatment

\begin{tabular}{|c|c|c|c|}
\hline \multirow[t]{2}{*}{ Characteristic } & \multicolumn{2}{|c|}{ All patients median (range) } & \multirow[t]{2}{*}{$P$ value } \\
\hline & $\begin{array}{l}\text { Subjects completing } \\
\text { treatment }(N=24)\end{array}$ & $\begin{array}{l}\text { Subjects not completing } \\
\text { treatment }(N=|2|)\end{array}$ & \\
\hline Age (years) & $51(29-64)$ & $52(26-64)$ & 1.0 \\
\hline Social support score ${ }^{a}$ & $67(18-100)$ & $60(18-100)$ & 0.54 \\
\hline HCV-related quality of life ${ }^{\mathrm{b}}$ & $34(0-77)$ & $18(0-77)$ & 0.27 \\
\hline Trust in physician ${ }^{c}$ & $67(45-98)$ & $77(48-100)$ & 0.08 \\
\hline Choice predisposition $^{d}$ & $10(4-10)$ & $10(5-10)$ & 0.84 \\
\hline
\end{tabular}

Notes: ${ }^{a}$ Based on a previously validated social support scale consisting of 18 questions. Range of total score is $0-100$ with higher scores representing greater social support; bbased on a previously validated hepatitis $\mathrm{C}(\mathrm{HCV})$ quality of life scale encompassing eleven questions. Range of total score is $0-100$ with higher scores representing worse quality of life; 'based on a previously validated trust in physician scale. Range of total score is 0-100 with higher scores representing greater trust in physician; ${ }^{d}$ choice predisposition was ascertained based on a previously validated scale ranging from zero ( $\mathrm{l}$ am certain that I do not want to be treated) to ten (I am certain that I do want to be treated). Higher scores reflect greater preference towards undergoing treatment.

our population underscores the importance of developing newer therapies with more favorable toxicity and efficacy profiles. Improving treatment outcomes for patients with chronic HCV will require concerted efforts to (1) identify patients with severe disease who are reluctant to initiate therapy, (2) improve access for those wishing to initiate therapy, and most importantly, (3) develop newer therapies that both improve efficacy and reduce the burden of adverse events related to treatment.

\section{Acknowledgments}

BC: study design, data analysis and interpretation, drafting the original and revised manuscript; LF: study conception and planning, collection and interpretation of data, securing funding, overseeing study, and drafting/editing manuscript; GGT: study conception and planning, collection and interpretation of data, securing funding, overseeing study, and drafting/editing manuscript. All authors reviewed and approved the final draft submitted. This study was supported by the following grants: VA HSR\&D Grant IIR-03-062, NIH K23AR048826 to LF, and NIH P30-DK34989 and NIH DK02727 to GGT.

\section{Disclosure}

The authors report no conflicts of interest with this work.

\section{References}

1. Ghany MG, Strader DB, Thomas DL, Seeff LB; American Association for the Study of Liver Diseases. Diagnosis, management, and treatment of hepatitis C: an update. Hepatology. 2009;49(4):1335-1374.

2. Armstrong GL, Wasley A, Simard EP, McQuillan GM, Kuhnert WL, Alter MJ. The prevalence of hepatitis C virus infection in the United States, 1999 through 2002. Ann Intern Med. 2006;144(10):705-714.

3. Dominitz JA, Boyko EJ, Koepsell TD, et al. Elevated prevalence of hepatitis $\mathrm{C}$ infection in users of United States veterans medical centers. Hepatology. 2005;41(1):88-96.

4. Freeman AJ, Dore GJ, Law MG, et al. Estimating progression to cirrhosis in chronic hepatitis C virus infection. Hepatology. 2001; 34(4 Pt 1):809-816.
5. Fattovich G, Giustina G, Degos F, et al. Morbidity and mortality in compensated cirrhosis type C: a retrospective follow-up study of 384 patients. Gastroenterology. 1997;112(2):463-472.

6. Hu KQ, Tong MJ. The long-term outcomes of patients with compensated hepatitis $\mathrm{C}$ virus-related cirrhosis and history of parenteral exposure in the United States. Hepatology. 1999;29(4):1311-1316.

7. Shindo M, Hamada K, Oda Y, Okuno T. Long-term follow-up study of sustained biochemical responders with interferon therapy. Hepatology. 2001;33(5):1299-1302.

8. Yoshida H, Arakawa Y, Sata M, et al. Interferon therapy prolonged life expectancy among chronic hepatitis C patients. Gastroenterology. 2002;123(2):483-491.

9. Bruno S, Stroffolini T, Colombo M, et al; Italian Association of the Study of the Liver Disease (AISF). Sustained virological response to interferon-alpha is associated with improved outcome in HCV-related cirrhosis: a retrospective study. Hepatology. 2007;45(3):579-587.

10. Fried MW, Shiffman ML, Reddy KR, et al. Peginterferon alfa-2a plus ribavirin for chronic hepatitis C virus infection. New Engl J Med. 2002;347(13):975-982.

11. Ghany MG, Nelson DR, Strader DB, Thomas DL, Seeff LB; American Association for Study of Liver Diseases. An update on treatment of genotype 1 chronic hepatitis $C$ virus infection: 2011 practice guideline by the American Association for the Study of Liver Diseases. Hepatology. 2011;54(4):1433-1444.

12. McHutchison JG, Everson GT, Gordon SC, et al; PROVE1 Study Team. Telaprevir with peginterferon and ribavirin for chronic HCV genotype 1 infection. N Engl J Med. 2009;360(18):1827-1838.

13. Hézode C, Forestier N, Dusheiko G, et al; PROVE2 Study Team. Telaprevir and peginterferon with or without ribavirin for chronic $\mathrm{HCV}$ infection. N Engl J Med. 2009;360(18):1839-1850.

14. Kwo PY, Lawitz EJ, McCone J, et al; SPRINT-1 investigators. Efficacy of boceprevir, an NS3 protease inhibitor, in combination with peginterferon alfa- $2 \mathrm{~b}$ and ribavirin in treatment-naive patients with genotype 1 hepatitis C infection (SPRINT-1): an open-label, randomised, multicentre phase 2 trial. Lancet. 2010;376(9742): 705-716.

15. Poordad F, McCone J Jr, Bacon BR, et al; SPRINT-2 Investigators. Boceprevir for untreated chronic HCV genotype 1 infection. $N$ Engl J Med. 2011;364(13):1195-1206.

16. Jacobson IM, McHutchison JG, Dusheiko G, et al; ADVANCE Study Team. Telaprevir for previously untreated chronic hepatitis $\mathrm{C}$ virus infection. N Engl J Med. 2011;364(25):2405-2416.

17. Sherman KE, Flamm SL, Afdhal NH, et al; ILLUMINATE Study Team. Response-guided telaprevir combination treatment for hepatitis $\mathrm{C}$ virus infection. N Engl J Med. 2011;365(11):1014-1024.

18. Morrill JA, Shrestha M, Grant RW. Barriers to the treatment of hepatitis C. Patient, provider, and system factors. J Gen Intern Med. 2005;20(8):754-758. 
19. Butt AA, Wagener M, Shakil AO, Ahmad J. Reasons for non-treatment of hepatitis C in veterans in care. J Viral Hepat. 2005;12(1):81-85.

20. Falck-Ytter Y, Kale H, Mullen KD, Sarbah S, Sorescu L, McCullough AJ. Surprisingly small effect of antiviral treatment in patients with hepatitis C. Ann Intern Med. 2002;136(4):288-292.

21. Shehab TM, Orrego M, Chunduri R, Lok AS. Identification and management of hepatitis $\mathrm{C}$ patients in primary care clinics. Am J Gastroenterol. 2003;98(3):639-644.

22. Butt AA, Justice AC, Skanderson M, Rigsby MO, Good CB, Kwoh CK. Rate and predictors of treatment prescription for hepatitis C. Gut. 2007;56(3):385-389.

23. National Institutes of Health Consensus Development Conference Statement: Management of hepatitis C: June 10-12, 2002. Hepatology. 2002;36(5 Suppl 1):S3-S20.

24. Fried MW. Side effects of therapy of hepatitis $\mathrm{C}$ and their management. Hepatology. 2002;36(5 Suppl 1):S237-S244.

25. McHutchison JG, Manns MP, Muir AJ, et al; PROVE3 Study Team. Telaprevir for previously treated chronic HCV infection. N Engl J Med. 2010;362(14):1292-1303.

26. Department of Veterans Affairs Hepatitis C Resource Center, Yee HS, Currie SL, Darling JM, Wright TL. Management and treatment of hepatitis $\mathrm{C}$ viral infection: recommendations from the Department of Veterans Affairs Hepatitis C Resource Center program and the National Hepatitis C Program office. Am J Gastroenterol. 2006;101(10):2360-2378.

27. Fraenkel L, Chodkowski D, Lim J, Garcia-Tsao G. Patients' preferences for treatment of hepatitis C. Med Decis Making. 2010;30(1):45-57.

28. Batts KP, Ludwig J. Chronic hepatitis. An update on terminology and reporting. Am J Surg Pathol. 1995;19(12):1409-1417.

29. Buchsbaum DG, Buchanan RG, Centor RM, Schnoll SH, Lawton MJ. Screening for alcohol abuse using CAGE scores and likelihood ratios. Ann Intern Med. 1991;115(10):774-777.

30. Ewing JA. Detecting alcoholism. The CAGE questionnaire. JAMA. 1984;252(14):1905-1907.

31. Mayfield D, McLeod G, Hall P. The CAGE questionnaire: validation of a new alcoholism instrument. Am J Psychiatry. 1974;131(10): 1121-1213.
32. Sherbourne CD, Stewart AL. The MOS social support survey. Soc Sci Med. 1991;32(6):705-714.

33. Ware JE, Snow KK, Kosinski M, Gandek B. SF-36 Health Status Survey Manual. Boston, MA: The Health Institute, New England Medical Center; 1993.

34. Kao AC, Green DC, Zaslavsky AM, Koplan JP, Cleary PD. The relationship between method of physician payment and patient trust. JAMA. 1998;280(19):1708-1714.

35. Bayliss MA, Gandek B, Bungay KM, Sugano D, Hsu MA, Ware JE Jr. A questionnaire to assess the generic and disease-specific health outcomes of patients with chronic hepatitis C. Qual Life Res. 1998;7(1): $39-55$.

36. Meenan RF, Gertman PM, Mason JH. Measuring health status in arthritis. The arthritis impact measurement scales. Arthritis Rheum. 1980;23(2):146-152.

37. Whooley MA, Avins AL, Miranda J, Browner WS. Case-finding instruments for depression. Two questions are as good as many. J Gen Intern Med. 1997;12(7):439-445.

38. O'Connor AM, Tugwell P, Wells GA, et al. A decision aid for women considering hormone therapy after menopause: decision support framework and evaluation. Patient Educ Couns. 1998;33(3):267-279.

39. Cawthorne $\mathrm{CH}$, Rudat KR, Burton MS, et al. Limited success of $\mathrm{HCV}$ antiviral therapy in United States veterans. Am J Gastroenterol. 2002;97(1):149-155.

40. Seal KH, Currie SL, Shen H, et al. VA HCV-001 Study Group. Hepatitis $\mathrm{C}$ treatment candidacy and outcomes among 4318 US veterans with chronic hepatitis $\mathrm{C}$ virus infection: does a history of injection drug use matter? J Clin Gastroenterol. 2007;41(2):199-205.

41. Manns MP, McHutchison JG, Gordon SC, et al. Peginterferon alfa- $2 b$ plus ribavirin compared with interferon alfa- $2 \mathrm{~b}$ plus ribavirin for initial treatment of chronic hepatitis C: a randomised trial. Lancet. 2001;358(9286):958-965.

42. Romero-Gómez M, Del Mar Viloria M, Andrade RJ, et al. Insulin resistance impairs sustained response rate to peginterferon plus ribavirin in chronic hepatitis C patients. Gastroenterology. 2005;128(3): 636-641.
Patient Preference and Adherence

\section{Publish your work in this journal}

Patient Preference and Adherence is an international, peer-reviewed, open access journal focusing on the growing importance of patient preference and adherence throughout the therapeutic continuum. Patient satisfaction, acceptability, quality of life, compliance, persistence and their role in developing new therapeutic modalities and compounds to

\section{Dovepress}

optimize clinical outcomes for existing disease states are major areas of interest. This journal has been accepted for indexing on PubMed Central. The manuscript management system is completely online and includes a very quick and fair peer-review system. Visit http://www.dovepress.com/ testimonials.php to read real quotes from published authors. 